\title{
BMJ Open Factors associated with the referral of children with severe illnesses at primary care level in Ethiopia: a cross- sectional study
}

\author{
Habtamu Beyene (D) , ${ }^{1,2}$ Dejene Hailu Kassa, ${ }^{2}$ Henok Tadele, ${ }^{3}$ Lars Persson (D) ,4,5 \\ Atkure Defar (i) , 5,6 Della Berhanu (D) ${ }^{4,5}$
}

To cite: Beyene H, Kassa DH, Tadele $\mathrm{H}$, et al. Factors associated with the referral of children with severe illnesses at primary care level in Ethiopia: a cross-sectional study. BMJ Open 2021;11:e047640. doi:10.1136/ bmjopen-2020-047640

- Prepublication history and additional online supplemental material for this paper are available online. To view these files, please visit the journal online. To view these files, please visit the journal online (http://dx.doi.org/10.1136/ bmjopen-2020-047640)

Received 05 December 2020 Accepted 26 May 2021

Check for updates

(C) Author(s) (or their employer(s)) 2021. Re-use permitted under CC BY. Published by BMJ.

For numbered affiliations see end of article.

Correspondence to

Mr Habtamu Beyene;

habtamu3346@yahoo.com

\section{ABSTRACT}

Context and objective Ethiopia's primary care has a weak referral system for sick children. We aimed to identify health post and child factors associated with referrals of sick children 0-59 months of age and evaluate the healthcare providers' adherence to referral guidelines. Design A cross-sectional facility-based survey. Setting This study included data from 165 health posts in 52 districts in four Ethiopian regions collected from December 2018 to February 2019. The data included interviews with health extension workers, assessment of health post preparedness, recording of global positioning system (GPS)-coordinates of the health post and the referral health centre, and reviewing registers of sick children treated during the last 3 months at the health posts. We analysed the association between the sick child's characteristics, health post preparedness and distance to the health centre with referral of sick children by multivariable logistic regressions.

Outcome measure Referral to the nearest health centre of sick young infants aged $0-59$ days and sick children 2-59 months.

Results The health extension workers referred 39/229 $(17 \%)$ of the sick young infants and $78 / 1123(7 \%)$ of the older children to the next level of care. Only $18(37 \%)$ sick young infants and 22 (50\%) 2-59 months children that deserved urgent referral according to guidelines were referred. The leading causes of referral were possible serious bacterial infection and pneumonia. Those being classified as a severe disease were referred more frequently. The availability of basic amenities (adjusted OR, $\mathrm{AOR}=0.38,95 \% \mathrm{Cl} 0.15$ to 0.96$)$, amoxicillin ( $\mathrm{AOR}=0.41$, $95 \% \mathrm{Cl} 0.19$ to 0.88 ) and rapid diagnostic test $(\mathrm{AOR}=0.18$, $95 \% \mathrm{Cl} 0.07$ to 0.46 ) were associated with less referral in the older age group.

Conclusion Few children with severe illness were referred from health posts to health centres. Improving the health posts' medicine and diagnostic supplies may enhance adherence to referral guidelines and ultimately reduce child mortality.

\section{INTRODUCTION}

Globally, nearly 5.3 million children below the age of 5 years died in 2018. Of these deaths, $47 \%$ occurred during the first month of life.
Strengths and limitations of this study

- Based on secondary analysis of register data from 165 health posts in 52 districts of the four most populous regions of Ethiopia, this study reports primary care referral patterns and associated factors in rural areas.

- This study used objectively measured data based on the WHO health service availability and readiness assessment tool and information obtained from the surveyed health posts compared with the national guidelines on referral.

- Using a cross-sectional study design, we cannot prove any causal relationship between the health post readiness, child factors and referral of sick children observed in this study.

- As the study was mainly based on register reviews, incomplete documentation of some of the health facilities might lead to reporting bias.

- The study findings do not give a complete picture of the country's referral system as we limited the analysis to the primary healthcare level, and we did not collect data from parents of the referred children.

More than half of this mortality occurred in sub-Saharan Africa. Infectious diseases remained the leading causes of death. ${ }^{1}$

Ethiopia achieved a significant reduction in child mortality during the Millennium Development Goals era from 1990 to $2015 .^{2}$ However, under 5 and neonatal mortality rates remain high with 55 and 30 deaths per 1000 live births, respectively. ${ }^{3}$ Lower respiratory tract infection, diarrhoeal diseases and neonatal causes (mainly preterm birth complications, asphyxia and neonatal sepsis), were the leading causes of death. ${ }^{4}$

The integrated case management of childhood illnesses and the community based newborn care programmes are, if delivered with quality, cost-effective in reducing under 5 deaths. ${ }^{56}$ Referral is included as a critical element in these programmes. ${ }^{7}$ In Ethiopia, 
the integrated community case management programme was initiated in 2010. ${ }^{8}$ This programme trained health extension workers to assess, classify, and treat sick children 2-59 months of age with pneumonia, diarrhoea, malnutrition and other common illnesses and refer severe cases to health centres according to guidelines. ${ }^{9}$ In 2013, the Community-Based Newborn Care programme was initiated. Health extension workers were trained to provide pre-referral antibiotic treatment for young infants (0-59 days) with possible severe bacterial infection and refer those to a higher-level facility. If a referral was not possible, the health workers were instructed to provide a 7-day antibiotic treatment. These interventions have been implemented in Ethiopia within the existing Health Extension Programme. ${ }^{6} 10$

A referral is defined as 'a process in which a health worker at one level of the health system, having insufficient resources (drugs, equipment, skills) to manage a clinical condition, seeks the assistance of a better or differently resourced facility at the same or higher level to assist in or take over the management of the client's case'. ${ }^{11}$ A well-functioning referral system is an essential part of the health system and an indicator of the quality of care provided at health facilities. ${ }^{7}$ The referral pattern may reflect the healthcare workers' ability to identify signs of severe illness at an early stage. ${ }^{12}$ For effective referral care, a prerequisite is also that the higher-level facility is ready to receive and treat these children appropriately. ${ }^{7}$

In a previous study, we showed that the Ethiopian health extension workers referred only a fraction of the severely sick young infants and under 5 children that deserved urgent referral to health centres. Generally, referral logistics were weak. ${ }^{13}$ Other studies in low-income countries have shown that the distance to the referral site, the severity of the child's illnesses ${ }^{14}$ and the availability of referral logistics ${ }^{15} 16$ may influence severely sick children's referral.

This study aimed to identify factors associated with the referral of severely ill children aged 0-59 months and healthcare providers' adherence to referral guidelines in Ethiopia's primary healthcare system. Specifically, we assessed the referral of sick children 0-59 months from health post to the next higher level of healthcare in relation to guidelines. We analysed factors associated with referral care, including child characteristics, health post preparedness and distance to the next-level health facility.

\section{METHODS}

\section{Study design and settings}

This study was based on data from the evaluation of Optimising the Health Extension Programme intervention. This intervention was a collaborative effort between the Government of Ethiopia and implementing partners to increase the use and quality of community-based newborn care and integrated community case management of childhood illnesses in four Ethiopian regions. ${ }^{17}$
We did a secondary analysis of data from the endline cross-sectional survey conducted in 26 districts, where the Optimising the Health Extension Programme intervention was implemented, and in 26 comparison districts without the intervention. These districts were found in four major Ethiopian regions, namely Amhara, Oromia, Southern Nations, Nationalities and Peoples and Tigray. The survey was conducted from December 2018 to February 2019, after the implementation of the intervention.

In Ethiopia, primary healthcare services are provided within the district health system, composed of five primary healthcare units and a district hospital serving around 100000 people. Each primary healthcare unit consists of five health posts and their referral health centre. The health post is typically staffed with two health extension workers and serves a population of 5000 people. ${ }^{18}$

The referral care of sick children 0-59 months of age from health posts to the next level was assessed in relation to the treatment guidelines for 0-59 days old sick young infants (community-based newborn care), and 2-59 months old children (integrated community case management).

According to these guidelines, babies $0-59$ days, who are very preterm ( $<32$ weeks), very low birth weight $(<1500 \mathrm{~g})$, preterm (32-37 weeks), low birth weight (1500-2500 g), have a possible severe bacterial infection, severe jaundice, severe dehydration, severe persistent diarrhoea or dysentery require an urgent referral. Similarly, children 2-59 months with a possible severe bacterial infection, severe dehydration, severe pneumonia, possible severe bacterial infections, severe persistent diarrhoea, very severe febrile disease, severe complicated measles, mastoiditis, severe anaemia and complicated severe acute malnutrition require an urgent referral. ${ }^{19}$

\section{Study population and sample}

The primary study had household and health facility modules to evaluate the Optimising the Health Extension Programme intervention. ${ }^{20}$ We used the 2007 Ethiopian census to select 200 enumeration areas proportional to the population size of the 52 districts included in the study. In the main study, households were randomly selected to represent the enumeration areas. The health posts serving the selected households were included in this study. All records of $0-59$ days old sick young infants, who sought care in 3 months prior to the survey, and records of the most recent ten 2-59 months sick children, who also sought care, were reviewed from treatment registers at the health post. Children without any illness who visited the health posts for postnatal care, vaccination, and growth monitoring were excluded from the analysis.

The sample size for the main study was based on the requirement that the baseline and end-line surveys should measure changes of a fixed number of percentage points of selected indicators for care-seeking and treatment for a sick child, based on household interviews. 


\section{Data collection}

The questionnaires used in this study were adapted from existing large-scale survey tools, such as the Demographic and Health Surveys and the Service Provision Assessment survey. ${ }^{21}$ Questionnaires were translated into three local languages (Amharic, Afan Oromo and Tigrigna) and pretested. All data were collected using tablet computers.

Out of the eligible 200 clusters, 19 clusters were excluded from the study due to civil unrest. Trained health professionals and supervisors collected the data.

We collected data on the number of health extension workers at the health posts, availability of amenities, equipment, supplies, diagnostics and medicines. Geographical positioning system coordinates were assessed at health posts and referral health centres. We reviewed registers of 0-59 days and 2-59 months old children and collected background data on their symptoms, disease classifications, treatment, and referral status.

\section{Patient and public involvement}

Not applicable (patients were not involved in this study).

\section{Data analysis}

A descriptive analysis was performed, including frequencies, percentages and means. We characterised the health posts, the distance from health posts to the referral health centres, the proportion of health posts with service readiness tracer items and referral logistics for childhood referral care, and the referral of sick children of 0-59 months from health posts to higher levels in relation to the treatment guidelines.

We used health posts and their respective referral health centres' GPS readings to calculate the two's straight-line distance. The health post's facility readiness was assessed using the WHO service availability and readiness assessment (SARA) reference manual. ${ }^{22}$ The general health facility service readiness has five domains, which include different tracer indicators, items and services. The first is basic amenities, including four items: communication, access to toilet facilities for clients, water source and power supply. The second is basic equipment with four items: infant or child scale, thermometer, functional stethoscope and mid-upper arm circumference tape measure. The third is standard precautions for infection prevention with seven items: sharps container, chlorine bleach, bucket for decontamination solution, contaminated waste container, soap and a towel or hand rub, alcohol-based hand rub and clean gloves. The fourth is the basic diagnostic capacity with a rapid diagnostic test for malaria. The last is essential medicines with ten items: vitamin $\mathrm{A}$, tetracycline eye ointment, gentamycin, amoxicillin, oral rehydration solution, zinc-oral rehydration solution combined, zinc and the ready-to-use therapeutic foods (plumpy nut and BP100). Finally, the combined facility service readiness was assessed using the general service readiness index by calculating five domains' mean score.
The attributes of the referred sick children, their symptoms, disease classification and treatment were analysed based on the existing treatment guidelines. ${ }^{19}$ Accordingly, the proportion of sick children with severe illnesses that require an urgent referral, non-severe illnesses that do not require urgent referral, the numbers referred and causes of their referrals were analysed. The referral status was linked with the facility readiness, and other health post factors, including the distance to the referral facility.

Referral of 0-59 days old sick young infants, and 2-59 months old children were the outcomes separately dichotomised as 'yes' (referred) or 'no' (not referred). $\chi^{2}$ tests were performed to assess whether the child's characteristics, health post preparedness and the distance to the next level health facility were associated with a sick child's referral. Relevant factors with statistically significant association to the referral of sick children in the bivariate analysis were entered into a multivariable logistic regression analysis to identify referral predictors. Adjustments were made for clustering and whether the cluster was an Optimising the Health Extension Programme intervention or comparison area. ORs with $95 \%$ CIs were calculated to measure the association between the predictor and outcome variables. Additionally, adherence to referral guidelines for sick young infants and older children was dichotomised as 'yes' (managed according to referral guideline) or 'no' (not managed according to referral guideline). Factors that had statistically significant association with referrals were then assessed in bivariate and multivariable logistic regression analyses to identify predictors of adherence to correct referral practices.

The Census and Survey Processing System software (United States Census Bureau, Washington DC, USA), was used to enter and edit survey data. Statistical analysis and tests were done using SPSS V.25 (SPSS, IBM).

\section{RESULTS}

We extracted data from treatment registers at 165 health posts serving 181 enumeration areas. Information on the assessment, treatment and referral of 229 sick young infants of 0-59 days and 1123 sick children aged 2-59 months was collected from the registers. Out of the 165 health posts, 48 had registered to manage one or more 0-59 days old sick young infants, and 147 had registered one or more 2-59 months old sick children in the 3 months preceding the survey.

\section{Characteristics of health posts}

Nearly $80 \%$ of health posts were staffed with two or more health extension workers, while the rest had only one. Almost all health posts had sick child registers, and $42 \%$ had referred at least one sick child to a health centre in the quarter before the survey. A cell phone signal was available in most of the surveyed health posts. Still, most health workers had neither used mobile phones nor other communication means for their most recent referral of a sick child (table 1). Half of the surveyed health posts were 
Table 1 Characteristics of health posts in four regions of Ethiopia (December 2018-February 2019) $(n=165)$

\begin{tabular}{lll}
\hline Characteristics & $\mathbf{n}$ & $\%$ \\
\hline Region & & \\
Amhara & 70 & 42 \\
Oromia & 48 & 29 \\
SNNPR & 22 & 13 \\
Tigray & 25 & 15
\end{tabular}

No of health extension worker per health post

\begin{tabular}{|lll|}
\hline 1 & 35 & 21 \\
\hline $2+$ & 130 & 79 \\
\hline $\begin{array}{lll}\text { Availability of } \\
\text { Registers for 0-59 days old children }\end{array}$ & 148 & 90 \\
\hline $\begin{array}{l}\text { Registers for 2-59 months old children } \\
\text { Cell phone signals in the health post }\end{array}$ & 156 & 95 \\
\hline $\begin{array}{l}\text { No of health posts that referred sick } \\
\text { children in the last quarter }\end{array}$ & 69 & 42 \\
\hline
\end{tabular}

Means of communication used for the referral of last sick child

\begin{tabular}{lll} 
Facility landline or mobile phone & 3 & 2 \\
Staff member's mobile phone & 25 & 15 \\
In person communication & 13 & 8 \\
\hline No communication for last child referral & 124 & 75 \\
\hline
\end{tabular}

SNNPR, Southern Nations, Nationalities and Peoples Region.

found within 10 kilometres from the next level referral health centre (figure 1). There were missing distance data for seven health posts.
Health post readiness status

The readiness of health posts to provide health services was assessed for five general service readiness domains. The average readiness score was $61 \%$ for basic amenities, $80 \%$ for basic equipment, $49 \%$ for standard precaution for infection prevention, $50 \%$ for basic diagnostic capacity, and $52 \%$ for essential medicines (figure 2). A significant proportion of the health posts lacked readiness to provide the required service for sick children, shown by an overall service readiness index of 57\%. Moreover, nearly half of the health posts did not have the required essential medicines. Even amoxicillin, which is needed to treat possible severe bacterial infection of 0-59 days sick young infants, was not available in a quarter of the health posts. Rapid diagnostic tests, which are highly important in malaria endemic areas like Ethiopia, was not found in half of the health posts (figure 2). The items included in these scores are shown in online supplemental figures 1-4).

\section{Referral of sick children}

During the last 3 months before the survey, 39 (17\%) of the 229 examined 0-59 days old sick young infants were referred from the health posts to the nearest health centres. Similarly, 78 (7\%) of the 1123 sick children aged 2-59 months old had been referred. Possible serious bacterial infection and pneumonia were the leading causes of referral among 0-59 days old and 2-59 months old children, respectively (table 2 ). Only $36 \%$ of $0-59$ day sick young infants with possible severe bacterial infection were referred. Similarly, the health extension workers referred only $27 \%$ of 2-59 months old children with severe malnutrition (table 2). Cross-tabulation of the four facility readiness domains and their respective individual components are shown in online supplemental tables 1 and 2 , respectively.

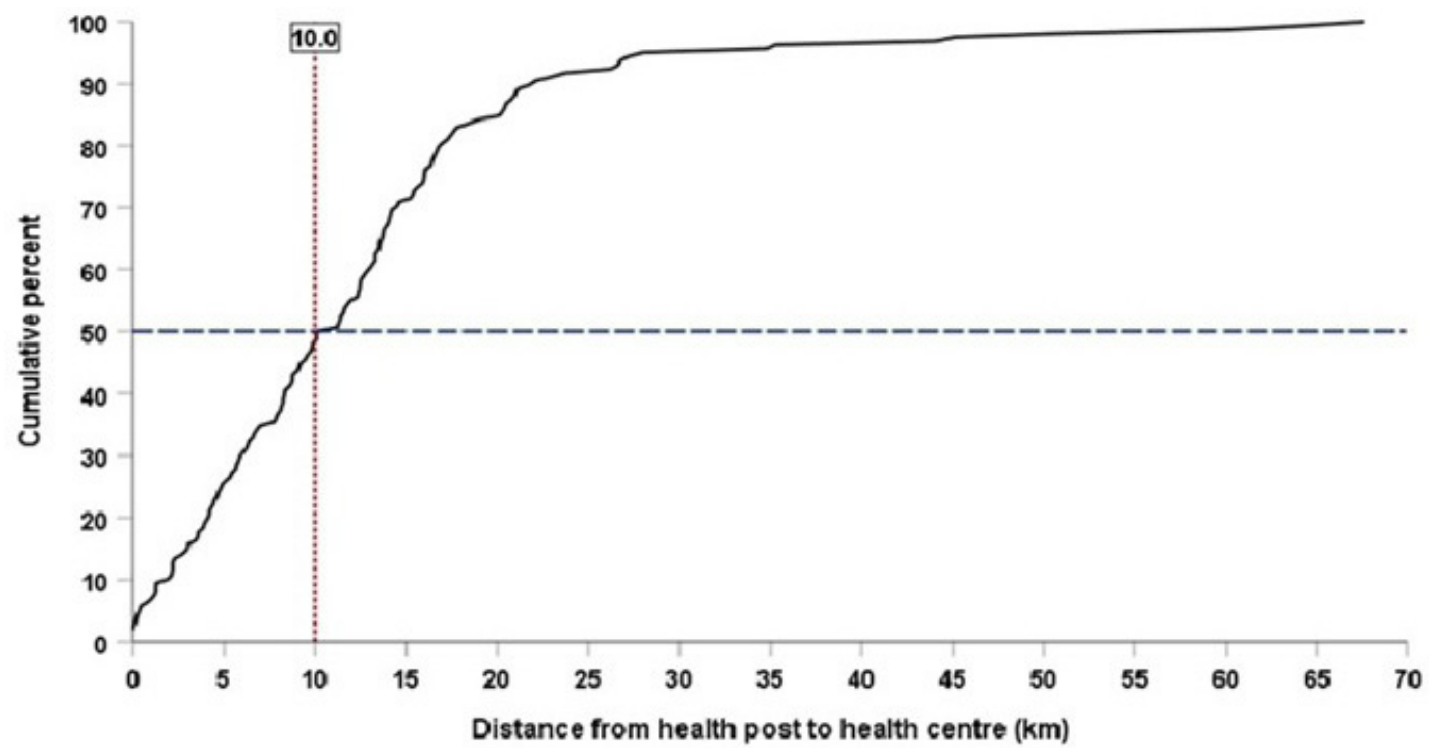

Figure 1 Cumulative percentages of distance from health posts to the referral health centres, analysed based on linear distance from 158 health posts to their 128 referral health centres. 


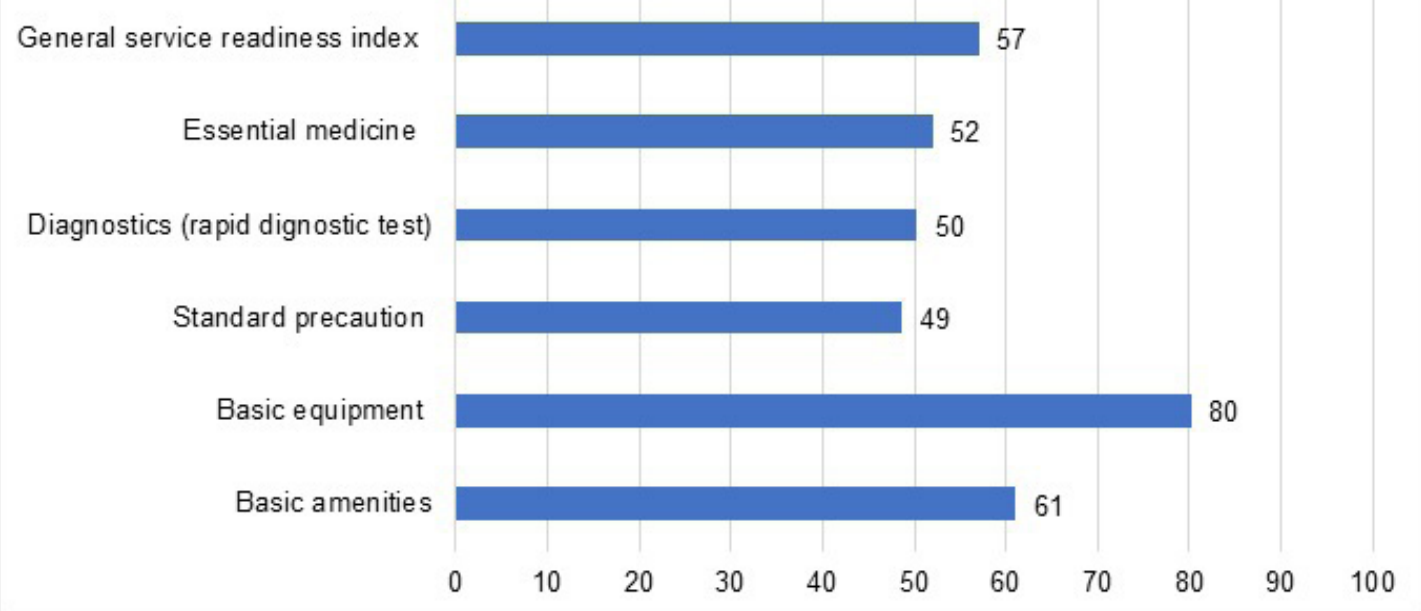

Figure 2 The mean percentage scores for five general service readiness domains of the surveyed 165 health posts analysed based on the WHO Service Availability and Readiness Assessment reference manual. ${ }^{22}$

\section{Factors associated with referral}

Sick young infants aged $0-59$ days with severe illnesses were seven times more likely to be referred to the next referral level, as compared with those with non-severe illnesses (95\% CI 1.50 to 30.11) (table 3). Sick young infants in the later weeks of life were less likely to be referred than those in the first week (adjusted OR, AOR $=0.25,95 \%$ CI 0.10 to $0.64)$. Neither the sex of the sick child nor the distance from health post to referral health centre were associated with referral (table 3). A higher proportion of sick young infants was referred from health posts served by two or more health extension workers than those served by only one $(p=0.024)$ (online supplemental table 1$)$.

Also, sick children aged 2-59 months with severe illness were more likely to be referred than those with non-severe illness (AOR=21.27, 95\% CI 7.51 to 60.23) (table 3). Health posts that had a better score for basic amenities were less likely to refer $2-59$ months sick children to the next level than those without $(\mathrm{AOR}=0.38,95 \% \mathrm{CI} 0.15$ to 0.96). Health posts with amoxicillin (AOR $=0.41,95 \% \mathrm{CI}$ 0.19 to 0.88$)$ and rapid diagnostic tests $(\mathrm{AOR}=0.18$, $95 \%$ CI 0.07 to 0.46 ) were less likely to refer $2-59$ months old children than those without these medicines and diagnostic kit.

The number of health extension workers, age and sex of the child and distance from health post to the referral health centre were not associated with referrals of 2-59 months old children.

\section{Management according to guideline}

The adherence to referral guidelines of sick young infants and older children is shown in table 4. Among the sick 229 young infants, 21 children were referred when a referral was not advised, and 31 children were treated at the health post when a referral was recommended. The remaining $177(77 \%)$ were managed according to referral guidelines. Of the factors associated with a referral, essential medicines were also associated with adhering to referral guidelines for young infants. Those in the higher tertile adhered more to referral guidelines (AOR $=13,95 \%$ CI 1.5 to 112.6). Among the 1123 sick older children, 56 were referred when a referral was not advised, and 22 children were treated at the health post when a referral was required. The remaining 945 (93\%) were managed according to referral guidelines. Facilities with amoxicillin and diagnostics were more likely to adhere to referral guidelines (amoxicillin $\mathrm{AOR}=2.8$, $95 \% \mathrm{CI} 1.3$ to 5.5 and diagnostics $\mathrm{AOR}=4.7,95 \% \mathrm{CI} 1.8$ to 11.9). Data for this analysis are shown in tables 5 and 6 .

\section{DISCUSSION}

Our study from four major Ethiopian regions showed that health extension workers referred only around onethird of the sick young infants 0-59 days old and half of the 2-59 months old children that should be referred, according to guidelines. The leading diagnoses at referral were possible severe bacterial infections in young infants and pneumonia in older children. As expected, conditions classified as severe were referred more frequently than non-severe cases. The tendency to refer was associated with some characteristics. For 0-59 days old infants, young neonates were referred more often than a bit older young infants. Health posts with basic amenities, amoxicillin, and rapid diagnostic tests were less inclined to refer older sick children. Within the 2-59 months group, age was not associated with referral. There was no sex difference in referral. Further, the straight-line distance from the health post to the health centre was not associated with referrals.

Due to the cross-sectional study design, we cannot prove any causal relationship between the health post and child factors that were associated with a referral of sick children. Further, we have analysed referral from the first primary care level, and are therefore only displaying part of the country's referral system. Exclusion of records of few sick children due to incomplete documentation on registers of some of the health facilities might be a limitation 
Table 2 Disease classification, recommended and performed referrals among children 0-59 months old seen at the surveyed 165 health posts, December 2018-February 2019

\begin{tabular}{|c|c|c|c|c|}
\hline Age group & Disease classification & $\begin{array}{l}\text { Referral guideline } \\
\text { supports referral? }\end{array}$ & No seen & No $(\%)$ referred \\
\hline \multirow[t]{16}{*}{$0-59$ days } & Very preterm or very low birth weight & Yes & 0 & 0 \\
\hline & Preterm or low birth weight & Yes & 4 & $2(50)$ \\
\hline & Possible serious bacterial infection & Yes & 42 & $15(36)$ \\
\hline & Severe dehydration & Yes & 0 & 0 \\
\hline & Severe persistent diarrhoea & Yes & 1 & 0 \\
\hline & Dysentery & Yes & 1 & $1(100)$ \\
\hline & Severe jaundice & Yes & 1 & 0 \\
\hline & Local bacterial infection & No & 59 & $5(9)$ \\
\hline & Some dehydration & No & 2 & $1(50)$ \\
\hline & No dehydration & No & 17 & $1(6)$ \\
\hline & Jaundice & No & 1 & 0 \\
\hline & Malaria & No & 0 & 0 \\
\hline & Feeding problem or low weight & No & 45 & $2(4)$ \\
\hline & Classification not given & - & 26 & 0 \\
\hline & Other ${ }^{*}$ & No & 30 & $12(40)$ \\
\hline & Total 0-59 days old & & 229 & $39(17)$ \\
\hline \multirow[t]{23}{*}{ 2-59 months } & Severe pneumonia/very severe disease & Yes & 9 & $8(89)$ \\
\hline & Severe dehydration & Yes & 2 & $1(50)$ \\
\hline & Severe persistent diarrhoea & Yes & 3 & $1(33)$ \\
\hline & Dysentery & Yes & 9 & $6(67)$ \\
\hline & Very severe febrile disease & Yes & 2 & $1(50)$ \\
\hline & Severe complicated measles & Yes & 0 & 0 \\
\hline & Severe malnutrition & Yes & 22 & $6(27)$ \\
\hline & Severe anaemia & Yes & 0 & 0 \\
\hline & Pneumonia & No & 478 & $16(3)$ \\
\hline & Some dehydration & No & 186 & $9(5)$ \\
\hline & No dehydration & No & 203 & 0 \\
\hline & Persistent diarrhoea & No & 28 & $2(7)$ \\
\hline & Malaria & No & 12 & 0 \\
\hline & Fever, malaria unlikely & No & 11 & 0 \\
\hline & Fever, no malaria & No & 55 & $4(7)$ \\
\hline & Measles with eye/mouth complications & No & 0 & 0 \\
\hline & Measles & No & 1 & $1(100)$ \\
\hline & Acute ear infection & No & 7 & $3(43)$ \\
\hline & Chronic ear infection & No & 1 & 0 \\
\hline & Moderate malnutrition & No & 33 & $4(12)$ \\
\hline & Anaemia & No & 1 & 0 \\
\hline & Others $†$ & No & 64 & $16(25)$ \\
\hline & Total 2-59 months old & & 1123 & $78(7)$ \\
\hline
\end{tabular}

*Other-classification for 0-59 days included 'infection unlikely' (12), 'eye problems' (10) and post natal care (PNC) cases with referral outcome (8).

†Others - classification for 2-59 months old children included mainly 'no pneumonia, cough' (42), and 'eye problems' (6), growth monitoring with referral outcomes (16). 


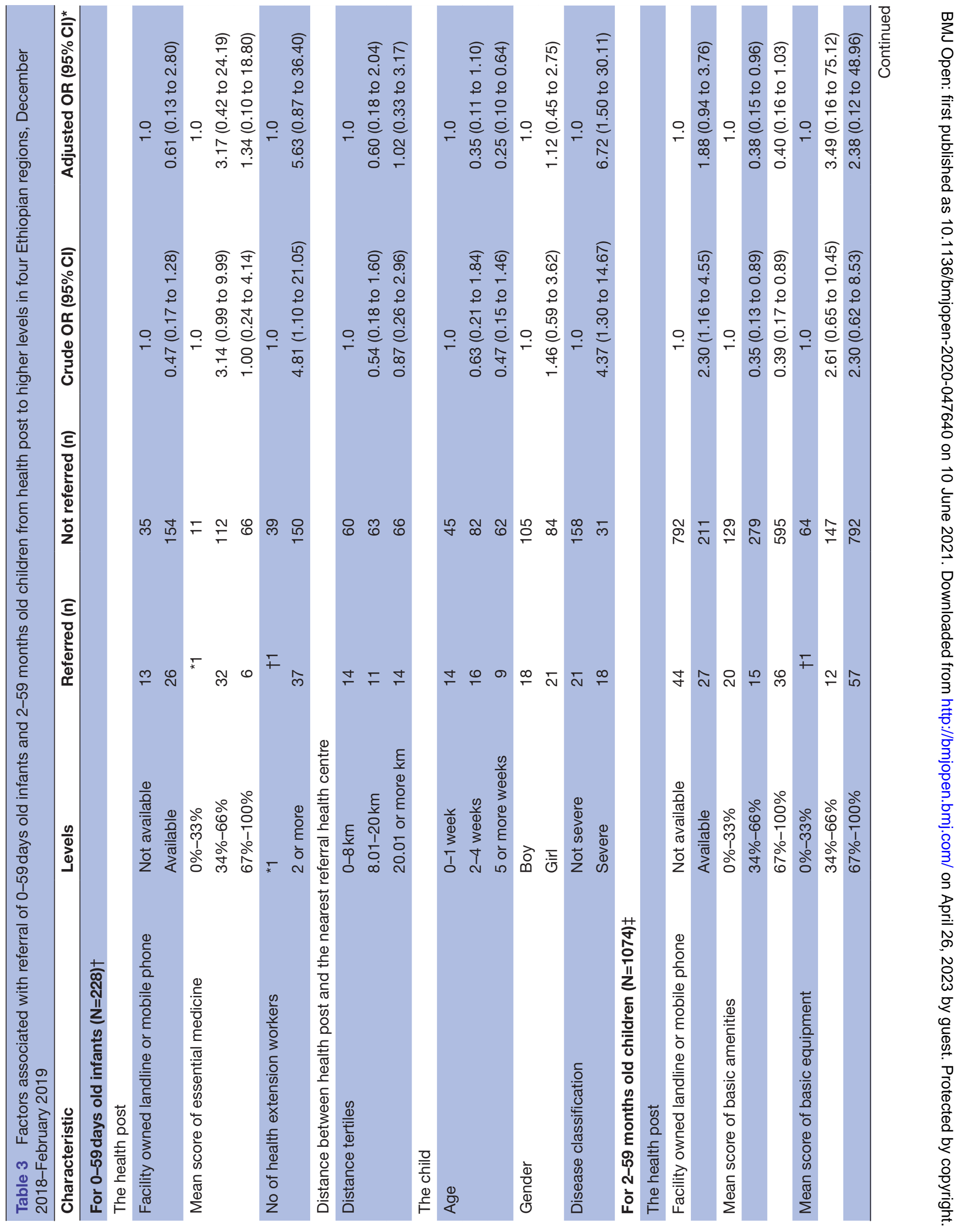




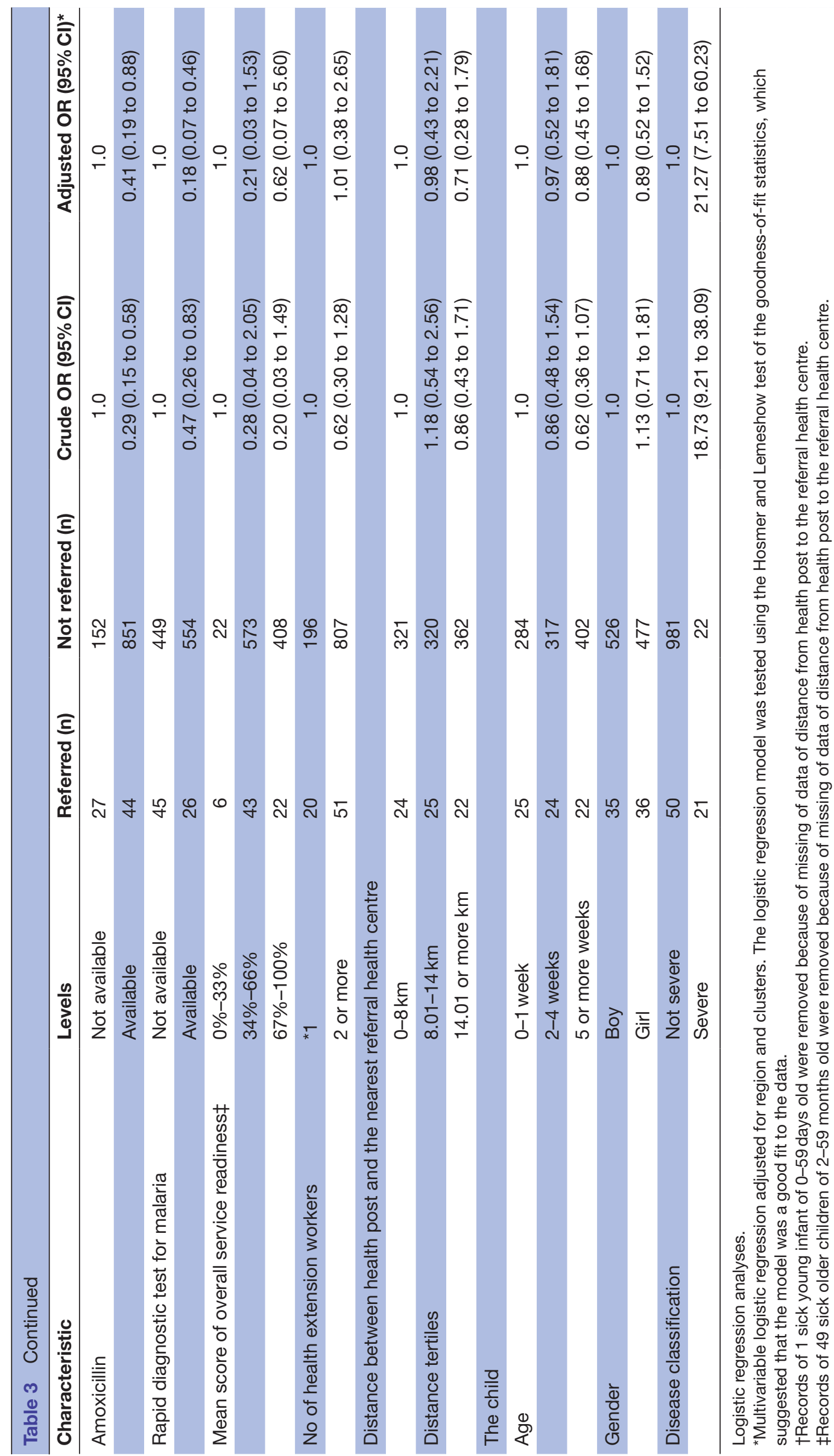


Table 4 Adherence to referral management guidelines for sick young infants and older children

\begin{tabular}{lllc}
\hline & Observed & \multicolumn{2}{l}{ Management guideline } \\
\cline { 2 - 4 } Age group & & $\begin{array}{l}\text { Referral } \\
\text { advised }\end{array}$ & $\begin{array}{l}\text { Referral } \\
\text { not } \\
\text { advised }\end{array}$ \\
\hline 0-59 days & Referred & 18 & 21 \\
& Not referred & 31 & 159 \\
2-59 months & Referred & 22 & 56 \\
& Not referred & 22 & 1023 \\
\hline
\end{tabular}

Note: Shadowed cells indicate referral management that did not adhere to guidelines.

which could lead to reporting bias. We used objectively measured data on the health posts, based on the WHO health SARA tool, and information obtained from the surveyed health posts were compared with national guidelines on referral. The study was performed in four of the largest regions in Ethiopia accounting for $80 \%$ of the population, where the enumeration areas were selected to represent the chosen districts of these regions. Though generalisation of the study findings to the regions might be difficult, it is expected that the selected districts did not differ in health systems characteristics.

Despite the WHO's recommendation, ${ }^{23}$ our study showed that only a third of young infants and half of the older children, who required referral, were referred from health post to the health centres. This finding was consistent with the previous Ethiopian and Malawian studies. ${ }^{92}$ The low referrals seen might be attributed to health providers' fear that caregivers would protest a referral, ${ }^{25}$ and the actual refusal of caregivers to comply with the referral. ${ }^{26}$ These factors might lead the health extension workers to manage the child at the health post. ${ }^{27}$ Healthcare providers might also undermine the overall impact of treatment guidelines on childhood survival. ${ }^{25} 28$ They may perceive that there is little added value in referral and even feel a loss of power and prestige when referring. ${ }^{29}$ They might also lack the knowledge and be reluctant to adhere to the guidelines. ${ }^{29}$ This low level of referral of severely sick children is concerning. It could delay access to appropriate care in the higher-level referral facilities, thus increasing the risk of death, ${ }^{30}$ and hinder the efforts to reach the sustainable development goals on neonatal and under-five mortality. ${ }^{31}$

In this study, the severity of a child's illness was associated with their referral in both age groups. ${ }^{32}$ This relation indicates that severely ill children were more frequently managed according to the referral guidelines. There is a need to strengthen health extension workers' ability to identify severely sick children requiring urgent referral. ${ }^{33}$ Neonates were primarily referred in their first week of life, highlighting the need for urgent referrals of severely ill newborns to prevent death in neonatal sepsis and other critical conditions. ${ }^{34}$. Also, we found that distance from health posts to health centre was not associated with referrals, perhaps since nearly three-quarters of the health posts were located within 15 kilometres from their referral health centre.

Lack of the overall readiness of the health posts to provide the required childcare services ${ }^{22}$ is an important finding of this study. This scenario could indicate that

Table 5 Factors associated with adherence to referral guidelines in the management of 0-59 days old sick young infants

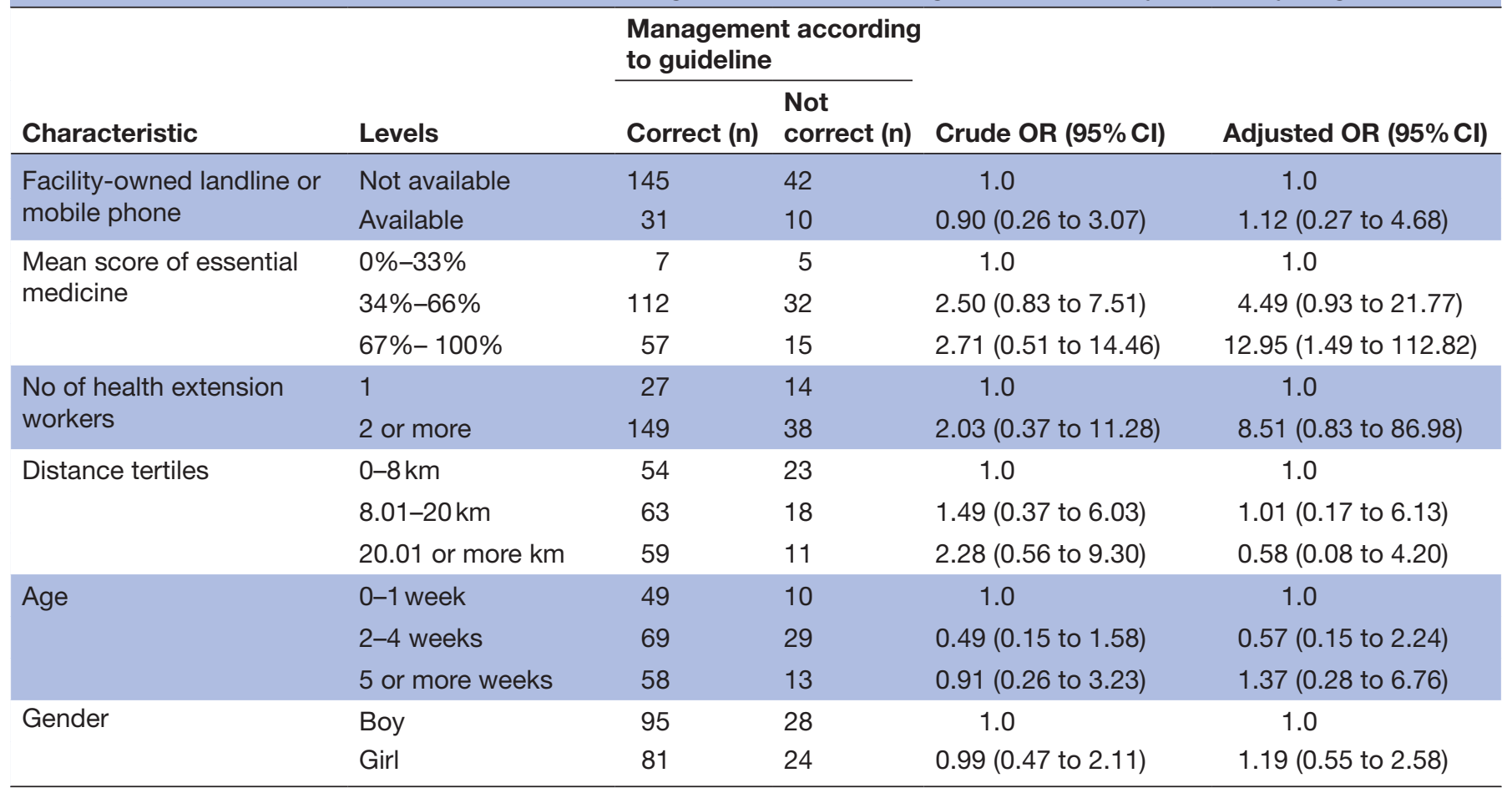


Table 6 Factors associated with adherence to referral guidelines in the management of 2-59 months old sick children

\section{Management according to} guideline

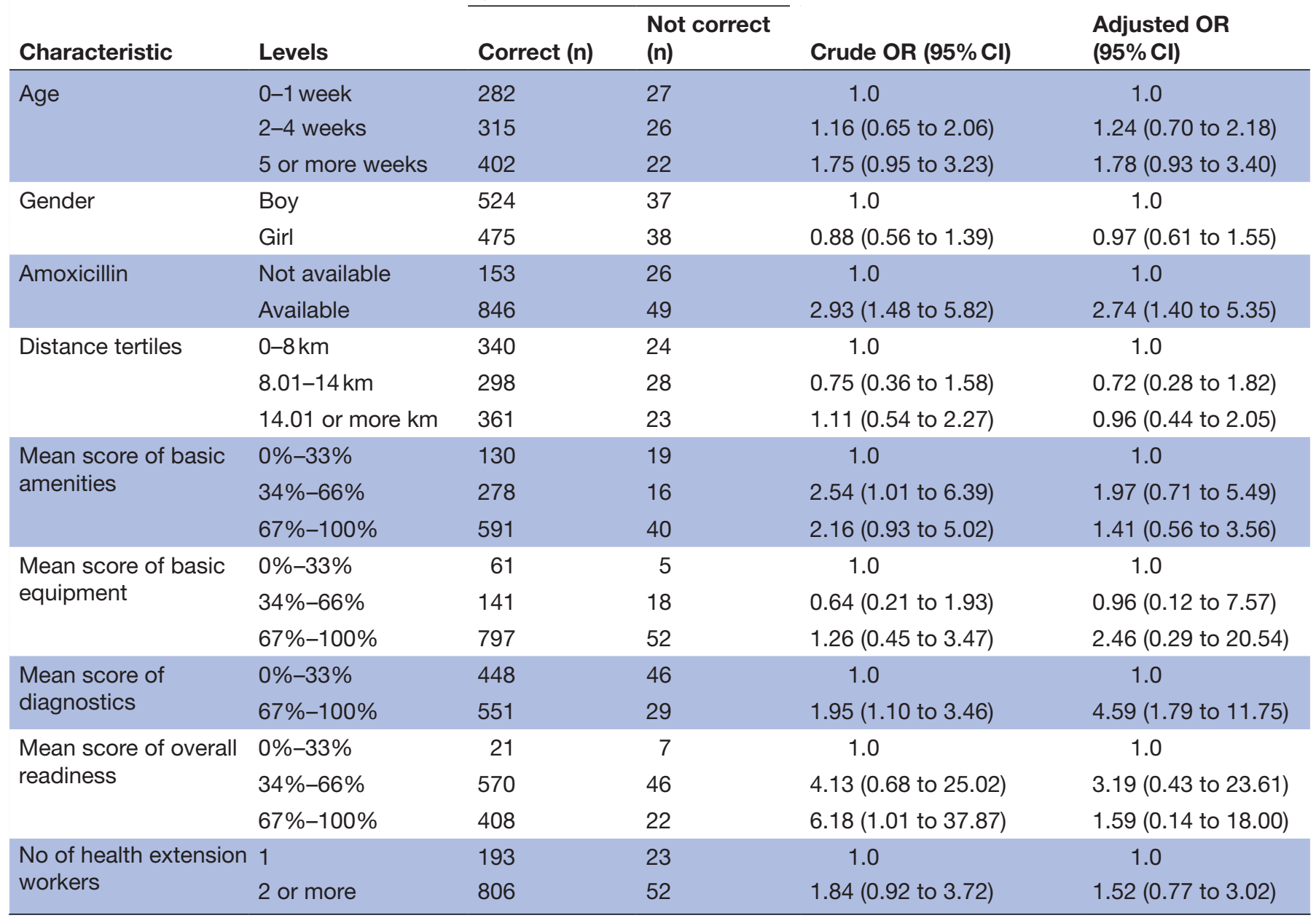

many care-seeking sick children were not getting the care they required, at least not at the health post. ${ }^{35}$ The lack of essential medicines might be a reason for some referrals of children with non-severe diseases, which otherwise may be treated at the first-level health facility. ${ }^{32} 36$ This condition might also impose caregiver for unnecessary social and economic costs incurred by referrals of children with non-severe illnesses. ${ }^{36} 37$

Indeed, our data also showed that health posts that had medicine and diagnostics were likely to adhere to referral guidelines. This calls for the need of equipping the health facilities with the basic essential medicines and diagnostics. Although not statistically significant in the multivariable analysis, health posts with two or more health extension works were also more likely to refer as well as adhere to referral guidelines for young infants. A study in Niger also found adequate staffing to be linked to adherence to referral guidelines. ${ }^{29}$

The non-adherence of the some of the healthcare providers to the referral guidelines when managing severely sick children found in this study requires improvement. This problem could result in overuse of antibiotics, and missing treatment or increased lethality in severe cases. ${ }^{38}$ Hence, mechanisms that can improve adherence to referral guidelines are needed as part of actions for improved quality of care.

\section{CONCLUSION}

We have shown that health extension workers referred few children with severe illnesses while a referral to the next-level health centre was recommended by guidelines. A significant proportion of the health posts were not ready to provide the necessary care, including referral. The severity of the child's illness, the availability of essential medicines and rapid diagnostic test were among the predictors of referrals of sick children from the health posts. Among other actions to enhance the quality of care provided at the health posts, improving medicine and diagnostic supplies may strengthen adherence to referral guidelines and ultimately prevent child deaths in Ethiopia.

Author affiliations

${ }^{1}$ Regional Health Bureau, Southern Nations Nationalities and Peoples' Region, Hawassa, Ethiopia 
${ }^{2}$ College of Medicine and Health Sciences, School of Public Health, Hawassa University, Hawassa, Sidama, Ethiopia

${ }^{3}$ College of Health Sciences, Department of Paediatrics and Child Health, Addis Ababa University, Addis Ababa, Ethiopia

${ }^{4}$ London School of Hygiene and Tropical Medicine, Faculty of Infectious and Tropical Diseases, London, UK

${ }^{5}$ Health System and Reproductive Health Research Directorate, Ethiopian Public Health Institute, Addis Ababa, Ethiopia

${ }^{6}$ Epidemiology and Biostatistics, Institute of Public Health, College of Medicine and Health Sciences, University of Gondar, Gondar, Ethiopia

Correction notice This article has been corrected since it was first published. The name for the author "Henok Tadele" has been corrected.

Acknowledgements We would like to extend our sincere gratitude to SNNP Regional Health Bureau and Hawassa University, College of Medicine and Health Sciences for providing support to conduct this research project. We would also like to pass our deepest appreciation to the different levels of the health systems and health providers involved in this study.

Contributors HB contributed to the conceptualisation of the study, design, development of the survey instrument, training and supervision of data collectors, statistical analysis and wrote the original draft and final versions of the manuscript. DHK and HDT contributed to the conceptualisation of the study design, development of the study instruments, supervision of the data collection process, data analysis and review of the different versions of the manuscript. DB and LP contributed to the conceptualisation of the study, design, development of the survey instrument, data compilation and statistical analysis, and reviewed the different versions of the paper. $A D$ contributed to the management of distance from health post to health centre data, development of the study instruments, supervision of the data collection process, and review of the different versions of the manuscript. All authors read and approved the final version of the manuscript.

Funding The study was supported by a grant from Bill and Melinda Gates Foundation to The London School of Hygiene and Tropical Medicine (grant OPP1132551).

Disclaimer The funder had no role in data collection, analysis, or interpretation of results.

Competing interests None declared.

Patient consent for publication Not required.

Ethics approval Ethical approvals were secured from the ethical review boards of Hawassa University (protocol number IRB/199/10; June 2018), the Ethiopian Public Health Institute (protocol number SERO-012-8-2016; V.001, August 2016) and the London School of Hygiene \& Tropical Medicine (protocol number 11235; June 2016).

\section{Provenance and peer review Not commissioned; externally peer reviewed.}

Data availability statement Data are available on reasonable request. Data may be obtained from a third party and are not publicly available. All data relevant to the study are included in the article or uploaded as online supplemental information. Data from this study are co-owned by the participating institutions and stored in a depository at the Ethiopian Public Health Institute (EPHI). The use of these data is guided by a data sharing agreement. Data can be accessed from the secretary of the data sharing committee of EPHI-LSHTM collaborative projects. Contact information: Martha Zeweldemariam, email: martha.zeweldemariam@Ishtm.ac.uk.

Supplemental material This content has been supplied by the author(s). It has not been vetted by BMJ Publishing Group Limited (BMJ) and may not have been peer-reviewed. Any opinions or recommendations discussed are solely those of the author(s) and are not endorsed by BMJ. BMJ disclaims all liability and responsibility arising from any reliance placed on the content. Where the content includes any translated material, BMJ does not warrant the accuracy and reliability of the translations (including but not limited to local regulations, clinical guidelines, terminology, drug names and drug dosages), and is not responsible for any error and/or omissions arising from translation and adaptation or otherwise.

Open access This is an open access article distributed in accordance with the Creative Commons Attribution 4.0 Unported (CC BY 4.0) license, which permits others to copy, redistribute, remix, transform and build upon this work for any purpose, provided the original work is properly cited, a link to the licence is given, and indication of whether changes were made. See: https://creativecommons.org/ licenses/by/4.0/.
ORCID iDs

Habtamu Beyene http://orcid.org/0000-0003-0923-5191

Lars Persson http://orcid.org/0000-0003-0710-7954

Atkure Defar http://orcid.org/0000-0001-9435-2135

Della Berhanu http://orcid.org/0000-0002-4984-893X

\section{REFERENCES}

1 United Nations Inter-agency Group for Child Mortality Estimation (UNIGME). Levels \& Trends in Child Mortality: Report 2019, Estimates developed by the United Nations Inter-agency Group for Child Mortality Estimation. New York United Nations Children's Fund; 2019.

2 Ruducha J, Mann C, Singh NS, et al. How Ethiopia achieved millennium development goal 4 through multisectoral interventions: a countdown to 2015 case study. Lancet Glob Health

2017;5:e1142-51.

3 Ethiopian Public Health Institute (EPHI) [Ethiopia] and ICF. Ethiopia mini demographic and health survey 2019: key indicators. Rockville, Maryland, USA EPHI and ICF; 2019. https://www.dhsprogram.com/ pubs/pdf/PR120/PR120.pdf [Accessed 24 Aug 2020].

4 Deribew A, Tessema GA, Deribe K, et al. Trends, causes, and risk factors of mortality among children under 5 in Ethiopia, 1990-2013: findings from the global burden of disease study 2013. Popul Health Metr 2016;14:42.

5 Mugeni C, Levine AC, Munyaneza RM, et al. Nationwide implementation of integrated community case management of childhood illness in Rwanda. Glob Health Sci Pract 2014;2:328-41.

6 Mathewos B, Owen H, Sitrin D, et al. Community-Based interventions for newborns in Ethiopia (combine): cost-effectiveness analysis. Health Policy Plan 2017;32:i21-32.

7 World Health Organisation. Standards for improving the quality of care for children and young adolescents in health facilities. Geneva World Health Organization; 2018.

8 Miller NP, Amouzou A, Tafesse M, et al. Integrated community case management of childhood illness in Ethiopia: implementation strength and quality of care. Am J Trop Med Hyg 2014;91:424-34.

9 Amouzou A, Hazel E, Shaw B, et al. Effects of the integrated community case management of childhood illness strategy on child mortality in Ethiopia: a cluster randomized trial. Am J Trop Med Hyg 2016;94:596-604.

10 Marsh DR, Hamer DH, Pagnoni F, et al. Introduction to a special supplement: evidence for the implementation, effects, and impact of the integrated community case management strategy to treat childhood infection. Am J Trop Med Hyg 2012;87:2-5.

11 World Health Organization. Referral Systems - a summary of key processes to guide health services managers, 2013. Available: https://www.who.int/management/facility/referral/en/ [Accessed 10 Aug 2020].

12 Price J, Willcox M, Kabudula CW, et al. Care pathways during a child's final illness in rural South Africa: findings from a social autopsy study. PLoS One 2019;14:e0224284.

13 Beyene H, Hailu D, Tadele H, et al. Insufficient referral practices of sick children in Ethiopia shown in a cross-sectional survey. Acta Paediatr 2020;109:1867-74.

14 Abrahim O, Linnander E, Mohammed $\mathrm{H}$, et al. A patient-centered understanding of the referral system in Ethiopian primary health care units. PLoS One 2015;10:e0139024-10.

15 Eskandari M, Abbaszadeh A, Borhani F. Barriers of referral system to health care provision in rural societies in Iran. $J$ Caring Sci 2013;2:229-36.

16 Akbari A, Mayhew A, Al-alawi MA, et al. Interventions to improve outpatient referrals from primary care to secondary care. Cochrane Database Syst Rev 2014;4:1-50.

17 Berhanu D, Okwaraji YB, Belayneh AB, et al. Protocol for the evaluation of a complex intervention aiming at increased utilisation of primary child health services in Ethiopia: a before and after study in intervention and comparison areas. BMC Health Serv Res 2020;20:339.

18 Global financing facility. Ethiopia health sector transformation plan (2015/16-2019/20). Available: https://www.globalfinancingfacility. org/ethiopia-health-sector-transformation-plan-201516-201920 [Accessed 22 Nov 2020].

$19 \mathrm{FMOH}$. Federal Ministry of health, Ethiopia. integrated management of newborn and childhood illness, part 1. blended learning module for the health extension programme, 2011. Available: https://www. open.edu/openlearncreate/-pluginfile.php/71990/-mod_resource/ content/2/IMNCl-_Part_1_Final_Print-ready_March_2011_.pdf [Accessed 15 Nov 2020]. 
20 Berhanu D, Okwaraji YB, Defar A, et al. Does a complex intervention targeting communities, health facilities and district health managers increase the utilisation of community-based child health services? A before and after study in intervention and comparison areas of Ethiopia. BMJ Open 2020;10:e040868.

21 Central Statistical Agency (CSA) [Ethiopia] and ICF. Ethiopia: demographic and health survey 2016, 2016. Available: https://www. dhsprogram.com/publications/-publication-FR328-DHS-FinalReports.cfm [Accessed 22 Nov 2020].

22 World Health Organization. Service availability and readiness assessment (SARA). An annual monitoring system for service delivery, 2015. Available: http://www.who.int/healthinfo/systems/ sara_indicators_questionnaire/en/ [Accessed 20 Oct 2020].

23 World Health Organization. Guideline: managing possible serious bacterial infection in young infants when referral is not feasible, world Health organization. Geneva, 2015. Available: https://apps.who.int/ iris/-handle/10665/181426 [Accessed 20 Oct 2020].

24 Amouzou A, Kanyuka M, Hazel E, et al. Independent evaluation of the integrated community case management of childhood illness strategy in Malawi using a national evaluation platform design. Am J Trop Med Hyg 2016;94:574-83.

25 Chinbuah MA, Abbey M, Kager PA, et al. Assessment of the adherence of community health workers to dosing and referral guidelines for the management of fever in children under 5 years: a study in Dangme West district, Ghana. Int Health 2013;5:148-56.

26 Hailegebriel TD, Mulligan B, Cousens S. Effect on neonatal mortality of newborn infection management at health posts when referral is not possible. Glob Heal Sci Pract 2017;5:202-16.

27 Wammanda RD, Adamu SA, Joshua HD, et al. Implementation of the WHO guideline on treatment of young infants with signs of possible serious bacterial infection when Hospital referral is not feasible in rural Zaria, Nigeria: challenges and solutions. PLoS One 2020;15:e0228718.

28 Wanduru P, Tetui M, Tuhebwe D, et al. The performance of community health workers in the management of multiple childhood infectious diseases in Lira, northern Uganda - a mixed methods cross-sectional study. Glob Health Action 2016;9:33194.

29 Bossyns P, Van LW. Human Resources for Health The weakest link : competence and prestige as constraints to referral by isolated nurses in rural Niger. BioMed Cent 2004;8:1-8.

30 Nabongo P, Verver S, Nangobi E, et al. Two year mortality and associated factors in a cohort of children from rural Uganda. BMC Public Health 2014;14:1-9.

31 Golding N, Burstein R, Longbottom J, et al. Mapping under-5 and neonatal mortality in Africa, 2000-15: a baseline analysis for the sustainable development goals. The Lancet 2017;390:2171-82.

32 Musa EO, Ejembi CL. Reasons and outcome of paediatric referrals from first- level health facilities in Sabongari, Zaria, northwestern. $J$ Community Med Prim Heal Care 2004;16:10-15.

33 Newbrander W, Ickx P, Werner R, et al. Compliance with referral of sick children: a survey in five districts of Afghanistan. BMC Pediatr 2012;12:1471-2431.

34 Rosenstock S, Katz J, Mullany LC, et al. Sex differences in morbidity and care-seeking during the neonatal period in rural southern Nepal. $J$ Health Popul Nutr 2015;33:1-10.

35 Getachew T, Abebe SM, Yitayal M, et al. Assessing the quality of care in sick child services at health facilities in Ethiopia. BMC Health Serv Res 2020;20:1-12.

36 Logaraj M. Management of referral services through computer based management system. Nat J Res Com Med 2013;2:1-4.

37 Nanyonjo A, Bagorogoza B, Kasteng F, et al. Estimating the cost of referral and willingness to pay for referral to higher-level health facilities: a case series study from an integrated community case management programme in Uganda. BMC Health Serv Res 2015;15:1-10.

38 Druetz T, Siekmans K, Goossens S. The community case management of pneumonia in Africa : a review of the evidence. Heal policy Planning 2013;2015:253. 